\title{
Foreign labor migration control in Russian regions using multicultural barometer (by the example of the Republic of Karelia)
}

\author{
Maria Pitukhina ${ }^{1,2, *}$, Oleg Tolstoguzov ${ }^{1}$, Lyubov Kulakova ${ }^{1}$, Eugene Pitukhin ${ }^{2}$, and Ivan \\ Radikov $^{3}$ \\ ${ }^{1}$ Karelian Research Center of Russian Science Academy, Petrozavodsk, Russia \\ ${ }^{2}$ Petrozavodsk State University, Petrozavodsk, Russia \\ ${ }^{3}$ St.Petersburg State University, Saint-Petersburg, Russia
}

\begin{abstract}
The article deals with foreign labor migration flows control as well as migration monitoring which are important for the Russian Federation regions'economy development. A new migration monitoring toolkit is proposed by the authors - Multicultural Barometer. It allows to quantify migration indicators in a region from 4 various angles: labor market; national identity; migrants' adaptation; migrants'integration. The research data is coming from open sources (Kareliastat, Federal Migration Service of the Republic of Karelia, Ministry of Labor and Employment of the Republic of Karelia, data obtained from Centers for Interethnic Cooperation in Karelian municipalities); both migrants' pilot survey and host community survey organized in 18 municipalities of the Republic of Karelia. The study conducted in Karelia seems to be important in a context of its geographical location (on a border with Finland) highlighting both successful practices and developing new tools for migration monitoring aimed at scientifically based solutions for migration control. Multicultural barometer as a tool was recommended by the Federal Agency on Ethnic Issues of Russia (FADN) and Strategic Initiatives Agency in 2017 as best regional practice for further implementation all over the Russian Federation.
\end{abstract}

\section{Introduction}

Difficulties in national goals achieving as well asstrategic tasks solving on in a current political cycle of the Russian Federation (2018-2024) are mainlyconditioned on by demographic problems: birth rate decrease (by 10.7\% in 2017) [1], natural population decline and number of working-age populationreduction. According to the Center for Strategic Research working-age population by 2030 would decrease from 11 million to 13 million people.

In these conditions foreign labor migration is considered as one of progressive resources for the Russian economy development. With a high degree of probability we might talk ona

\footnotetext{
*Corresponding author: maria.pitukhina@gmail.com
} 
possible large-scale migration growth in that part of the Russian regions, which due to stressed demographic situation are experiencing labor shortage.

A systemic upgrade of the entire migration control system in Russia is highly necessary.In order to develop a set of measures aimed at migration control upgrading the President of Russia V.V. Putin in his decree "Ensuring interethnic harmony" [2] called the Government for effective mechanisms aimed at interethnic conflicts resolving and system monitoring of interethnic relations.

As a result in October 2017 Russian Government has adopted Resolution "On State Information System development for Interethnic and Interfaith Relations Monitoring and Early Warning of Conflict Situations".

At the beginning of 2018 all Russian regions become inter-connected to state monitoring system of interethnic relations, and in 48 regions such work has been completed at municipal level [1]. Database for national monitoring system accounts more than 25 million of objects. It covers information on 90000 of media resources, 220000 of NGOs, 3 200Kazak organizations, 2100 of indigenous people communities. The system at federal level is useful for the Presidential Administration, the President plenipotentiaries in federal districts, Ministry of Internal Affairs of Russia, National Anti-Terrorism Committee, Ministry of Defense of Russia. Information for this monitoring system is provided by the Ministry of Internal Affairs, Ministry of Justice, Ministry of Culture, Ministry of Education and Science, Federal Security Service and Federal Service for Financial Monitoring. The system also provides a visual data by means of infographics- charts, graphs, figures.

System performance in Russian regions has unveiled the fact that some Russian regions faced serious difficulties during its application [3].

The article's research object deals with Multicultural barometer development - a tool for migration both monitoring and control in a region, as well as its further practical application by local executive authorities at the Republic of Karelia.

Research hypothesis deals with is authors'statement that Multicultural barometer as an innovative monitoring tool allows you to quantify a number of indicators characterizing migration: situation in a labor market, level of interethnic consent in a region, geographical distribution of migration tension, degree of migrants' adaptation and isolation. Thus, a regularly updated Multicultural barometer would create all the necessary conditions for migration policy successful performance in Russian regions.

\section{Literature Review}

Authors are familiar with both foreign and domestic outstanding practices of "barometers" implementation as a visual data representation tool: Euro Barometer, Latino Barometer, African Barometer, Arab Barometer, Occupational barometer (Finnish experience), European student barometer (Graduate Barometer Europe), Economic barometer at the Republic of Bashkortostan; Russian Government Resolution "On State Information System development for Interethnic and Interfaith Relations Monitoring and Early Warning of Conflict Situations".

Studies by $[4,5]$ shall be also mentioned since they are devoted to conflicts in multiethnic societies; papers by $[6,7,8,9,10,11]$ consider gravity aspects of migration flows.

The issues of migrants' integration in local communities are unveiled in papers of $[12,13,14,15,16]$. Papers of St.Petersburg sociologists [17] shall be also mentioned in terms ofcross-border practices and neighborhood phenomenon analysis by the examples of Finland and Russia $[18,19]$.

However, "barometer" implementation as a method for migration monitoring and control was not considered by them. Multicultural barometer as a tool for both interethnic 
relations and migration flows monitoring was described in dissertation by one of this paper authors- Dr. M.Pitukhina [20].

\section{Research Methodology}

While analyzing migration flows at a border region - the Republic of Karelia - it should be noted that traditionally Karelia was known as one of the most "calm" regions of the Russian Federation with a relatively low level of social and interethnic tension. However, in 2006 the Republic of Karelia became "famous" for the events happened in a small town of Kondopoga where acute ethnic conflict took place. Its resolution demanded bringing troops into a town.

According to data of the General Prosecutor's Office of the Russian Federation and Rosstat, the Republic of Karelia is ranked as seventh in the Top-10 "extremist" regions of the Russian Federation and the second with the highest percentage of extremist crimes per capita in 2015. This situation is a result of wrong implementation of both migration and national policies in the region. The following decade however the situation has significantly changed at the republic.

Thus, the following migration trends for the Republic of Karelia shall be mentioned: a) human resources quality deterioration as a result of a qualified human resources outflow to central regions of Russia and abroad b) retired human resources are replaced with a lowskilled staff (usually from the CIS); c) a combination of natural population decline with population migration outflow, especially youth; d) high population density in southern Karelia and at Petrozavodsk as well as population outflow from northern territories, e) increased demand for qualified HR together with high unemployment ratein municipalities with intensive migration outflows.

Table 1. Migration at the Republic of Karelia in 2013-2018 (people). Source: Karelijastat, pokazateli mezhdunarodnoj migracii, 2013-2018.

\begin{tabular}{|l|c|c|c|c|c|c|}
\hline & $\mathbf{2 0 1 3}$ & $\mathbf{2 0 1 4}$ & $\mathbf{2 0 1 5}$ & $\mathbf{2 0 1 6}$ & $\mathbf{2 0 1 7}$ & $\mathbf{2 0 1 8}$ \\
\hline $\begin{array}{l}\text { Arrived from other regions of } \\
\text { Russia }\end{array}$ & 6750 & 7287 & 7537 & 7913 & 8062 & 8377 \\
\hline Arrivedfromthe CIS & 1316 & 1559 & 1850 & 1500 & 1342 & 1269 \\
\hline Arrived from non-CIS countries & 484 & 486 & 426 & 431 & 329 & 284 \\
\hline Left to other regions of Russia & 8650 & 8666 & 9136 & 9160 & 9646 & 9547 \\
\hline Left to the CIS countries & 225 & 396 & 849 & 1186 & 1392 & 1175 \\
\hline Left to non-CIS countries & 473 & 710 & 562 & 506 & 611 & 528 \\
\hline
\end{tabular}

Migration legislation upgrading in 2015 had a significant impact on migration flows control. Starting from January 1, 2015 entry in Russia the CIS citizens who are not members of the Eurasian Union (by their national passports) was prohibited including Ukrainian citizens who are not refugees [21]. And even more significant limitations were introduced such as - examinations in Russian language, history of Russia and fundamentals of Russian law, medical insurance. Most of the introduced requirements are highly-paid limiting numbers of migrants who wish to come Russia to earn money.

The main donor-states of migration resources to the Republic of Karelia are Ukraine (2015-1161 people., 2016.-901 people., 2017.-774 people.) and Finland (2015 .-186 people, 2016.-210 people., 2017.-193 people). Let us make an assumption that high Human Development Index of migrants from these countries $($ Ukraine $=0.734$; Finland $=0.879$ ) allows them to adapt more easily to local characteristics, apriorithey are less conflicting.

It should be stated that barometers as a visual data representation tool has been very popular in both foreign and domestic practices. Barometers as a type of data representation have been more than 50 years old already (Euro Barometer, Latino Barometer, African 
Barometer, Arab Barometer). For example, Occupational barometer is being successfully implemented in Finland by the ELY-centers (Centers for Economic Development, Transport and Environment) to outline occupations which are in deficit, in proficit and in balance at municipal labour markets.

The European student barometer (so called Graduate Barometer Europe) conducted by a German research institute on "education and career" trajectory is also widely known. Occupational Barometer as a convenient tool in assessing current employment in a labor market is used in many regions of Russia. Economic barometer implementation is also known at the Republic of Bashkortostan [22].

Multicultural barometer development includes three stages:

1. Preliminary stage: principal actors' identification, barometer's data sources outlining.

2. Main stage: data collecting from open sources and migrants survey organization(questionnaires in both paper and electronic versions).

3. Final stage: regional context analysis, key migration trends systematization at regional level; identification of factors and measures for regional migration policy development.

Data for Multicultural barometer was provided by the Federal Migration Service at the Republic of Karelia; Kareliastat; Ministry of Labor and Employment of the Republic of Karelia; Centers of interethnic cooperation in Karelian municipalities; migrants' pilot survey results (sample amounted to $10 \%$ ); host community survey results (1,500 people).

Both host community and migrants surveys took place in 18 municipalities of the Republic of Karelia.

Migrants' survey sample was both representative and quota since it reflects general population characteristics by the following structure: gender, age, donor- states (countries of arrival). In bigger municipalities with more migrants the survey was conducted in proportion to their representation (quota sample). Migrants' survey reliability is accounted for $95 \%$ for all municipalities.

Host community survey sample was covering at least $0.1 \%$ of the population at the Republic of Karelia. The average value sample was strongly influenced by a population mood at Petrozavodsk; therefore, it is advisable to use average value taking into account territorial distribution of research indicators.

\section{Results}

In 2015 Multicultural barometer as a tool for migration policy monitoring was developed in the framework of the project "Concept of interethnic consent development at the Republic of Karelia: a joint platform for NGOs and authorities" (2014-2015). Multicultural barometer includes an integrated evaluation of migration policy in a region as a whole and geographical distribution of migration tension in terms of municipalities. Multicultural barometer provides actual information for decision-making in migration policy.

Multicultural barometer included the following modules ("labor market", "national identity", "migrants' social adaptation", "migrants' integration") (Figure 1). 


\begin{tabular}{|c|c|}
\hline $\begin{array}{l}\text { Criteria: } \\
\text { 1 Number of migrants per } 10000 \text { natives (statistics) } \\
\text { 2.Average migrants' age vs natives' average age (statistics) } \\
\text { 3.Migrants redistribution in accordance with types of } \\
\text { economic activity vs. natives' redistribution in types of } \\
\text { economic activity (statistics) } \\
\text { 4.Migrants' education level vs. natives' education level } \\
\text { (statistics) } \\
\text { 5.Number of unemployed migrants(statistics) }\end{array}$ & $\begin{array}{l}\text { "National Identity» } \\
\text { Criteria: } \\
\text { 1. Migrants' native language use (migrants survey data) } \\
\text { 2.Intensity of communication with compatriots (migrants } \\
\text { survey data) }\end{array}$ \\
\hline $\begin{array}{l}\text { «Migrants adaptation» } \\
\text { Criteria: } \\
\text { 1.Level of basic Russian language knowledge (statistics) } \\
\text { 2.Level of cross-cultural communication (migrants survey } \\
\text { data) } \\
\text { 3.Migrants' satisfaction with life quality (accommodation, } \\
\text { access to info) }\end{array}$ & $\begin{array}{l}\text { Criteria: } \\
\text { 1.Number of museums, theaters, exhibitions visited by } \\
\text { migrants (migrants survey data) } \\
\text { 2. Number of visits to Centers of international cooperation/ } \\
\text { Offices dealing with migrants / for consultations, help, cultural } \\
\text { events (Centers'/Offices data) }\end{array}$ \\
\hline
\end{tabular}

Fig. 1. Multicultural barometer's modules.

The proposed Multicultural barometer is a part of the Concept on Interethnic Consent developed by the Ministry on ethnic issues at the Republic of Karelia.

\section{Discussion}

The influx of foreign labor migrants into the Republic of Karelia seems relatively small comparing to other regions of the Russian Federation. As noted over the past 2 years migration balance of the Republic of Karelia has become positive due to migration flows from Ukraine. Total number of inter-regional, intra-regional, foreign labour migrants at the Republic of Karelia is 24,511 people, of which 3604 are foreign labor migrants (Figure 2).

We've tried to analyze data on both migrants' and host community level of education. Huge number of migrants with higher vocational education $(37.5 \%)$ come to the Republic of Karelia (Figure 2). This is also confirmed by the results of two focus groups conducted under the aegis of the Federal Migration Service at the Republic of Karelia in 2014 and 2016, where the main part participants were migrants mainly from Ukraine with higher education (doctors and teachers). A relatively high influx of specialists with secondary vocational education (51\%) is also recorded in Karelia. Currently Ministry of Labor and Employment of the Republic of Karelia can't provide any data on migrants' elementary vocational education assess (Figure 2). 

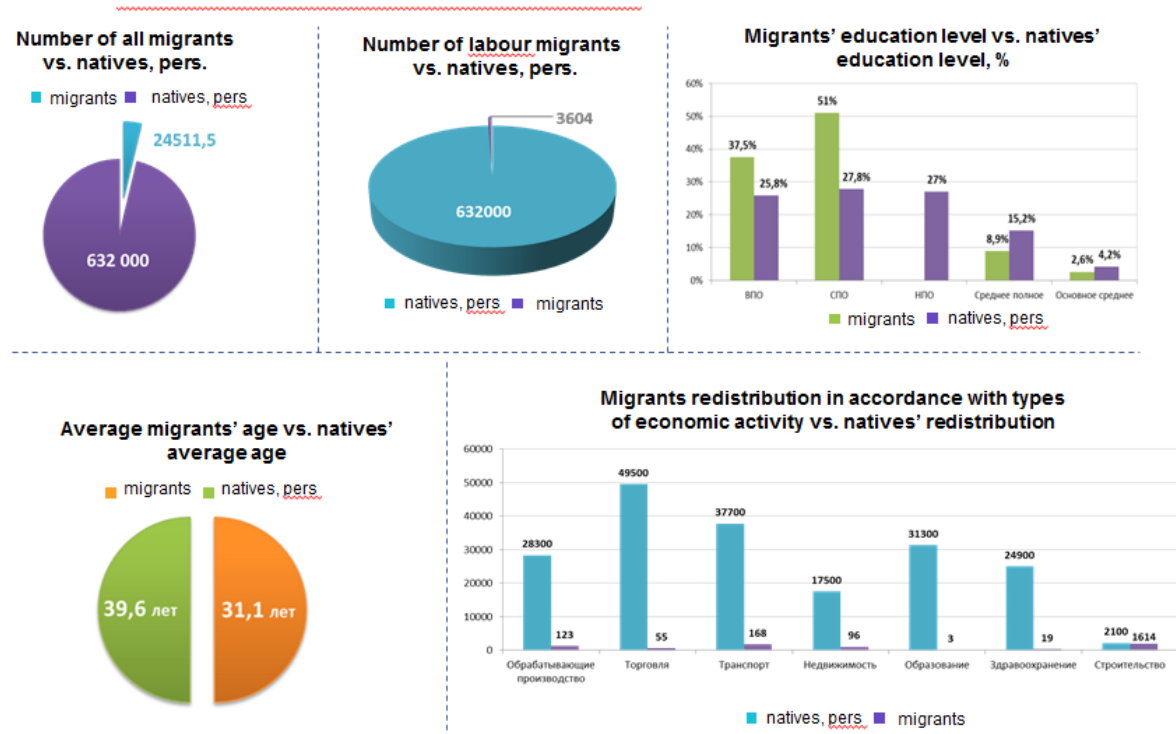

Fig. 2. Module «labor market» of Multicultural barometer.

Despite the fact that humanitarian migration prevails labor migration at the Republic of Karelia, still young people aged 30 years old come to Karelia to find a job place (Figure 2). Population of Karelia is aging, approaching 40 years old. Migrants of this age group (30+) do not carry any budget burden (they buy patents and pay taxes to regional budget). Migrants who come to Karelia often become "productive" citizens as some of them invest in small businesses and create job places for the host community. Most migrants at the Republic of Karelia seek to find a job and create conditions of a good education access for children [23].

We shall note that only one type of economic activity in Karelia- this is $\mathrm{F}$ "Construction" - where both migrants and host community are equally represented (Figure 2). In other types of economic activities - "Wholesale and retail trade", "Real estate operations and services", "Manufacturing", "Transport and communications", "Education", "Health and social services" numbers of migrants are several times less than of the host community representatives.

Migrants' pilot survey was carried out in 2016 in the framework of the project "Public and media monitoring as an influential tool upon interethnic processes" at the Republic of Karelia. This survey was conducted for the first time for migrants in all 18 municipalities of Karelia. Questionnaire included such topics as "national identity", "communication with compatriots", "cross-cultural communication", "migrant mother tongue", "migrant in a labor market". Questionnaire modules closely correlate with four developed modules of the Multicultural Barometer. Migrants sample in Karelia accounted for $9 \%$ of the total number of foreign labor migrants in a region. Diagram of surveyed migrants' redistribution is presented in Figure 3. Basically the survey involved migrants from Ukraine, Azerbaijan, and Uzbekistan. 

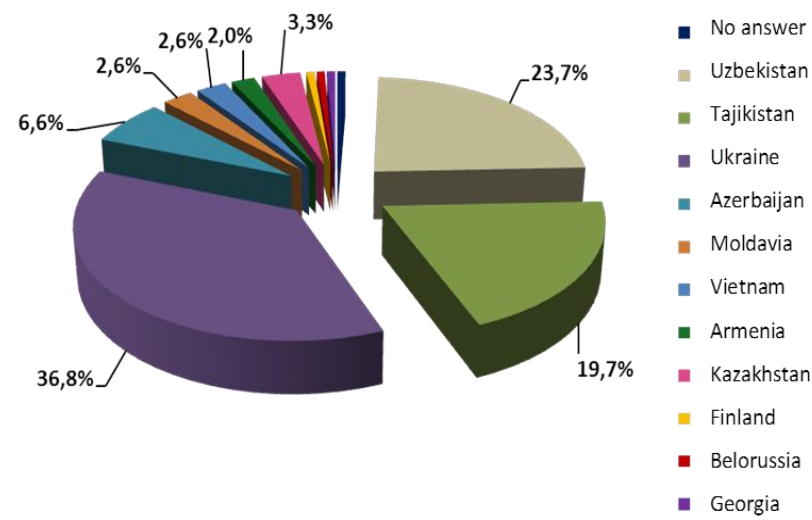

Fig. 3. Diagram of surveyed migrants' redistribution in Karelia.

According to migrants' survey results it became clear that migrants seek to maintain their "national identity" that is proved by intense communication in their native language (70.2\% of respondents). Interestingly but migrants mainly use telephone communications (74.3\%), then Skype (37.5\%) or social networks (25\%) to communicate with compatriots (Figure 4). Also, the results of piloted migrants survey and of two focus groups with migrants did confirm that migrants strive to maintain their national identity.

One of such criteria for national identity conservation is migrants' commitment to national cuisine. According to received data migrants from Armenia cook traditional food on everyday basis, migrants from Moldova - 2 times per week, migrants from Uzbekistan cook "plov" every Thursday.

In Multicultural barometer module "migrants' social adaptation" an attempt was made to assess migrants' quality of life. It became clear that migrants became satisfied with living conditions $(85.5 \%)$ (Figure 5). They got also satisfied with working conditions (almost $80 \%$ ), slightly less satisfied with salaries $(73.7 \%)$. While patent obtaining migrants faced the following difficulties - financial costs $(27 \%)$, document turnover $(27.6 \%)$, time costs (17.1\%). Answering the question "who helped you in finding a job" 57.2\% noted social networks (relatives and friends), 12.5\% claimed employment service (Figure 5). Traditionally migrants do not communicate with employment services, they try to avoid any interactions with government bodies. In its turn, the Republic of Karelia demonstrates pretty high rate here. 


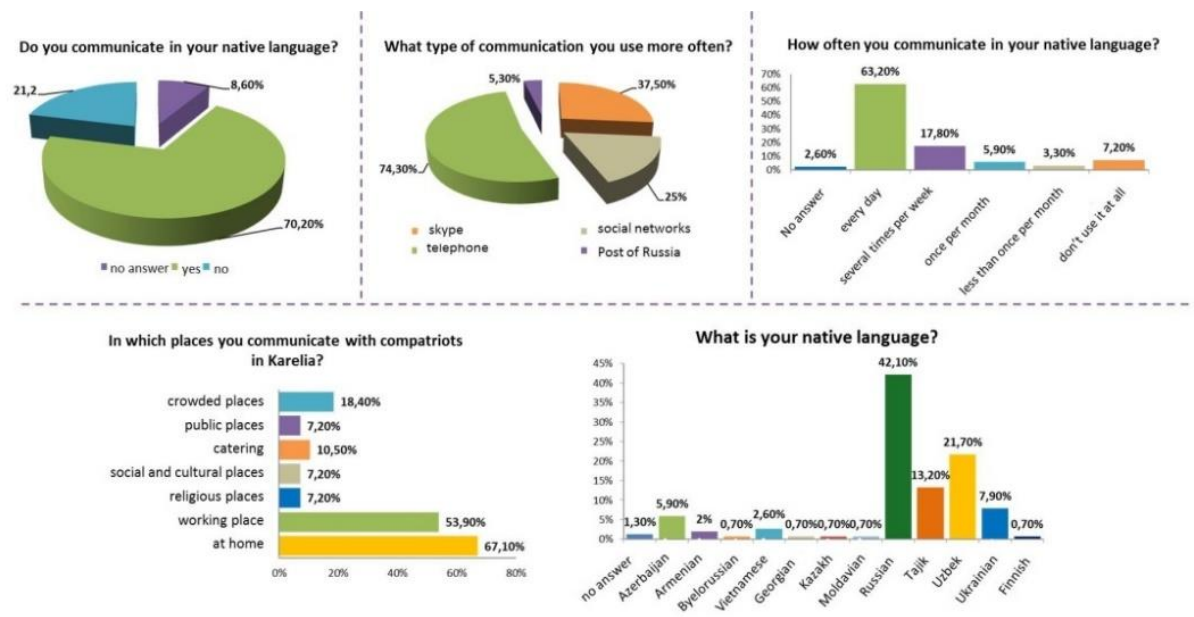

Fig. 4. Module «national identity» of Multicultural barometer.

It seems possible to categorize migrants of different ethnic groups-migrants from Central Asia come on a patent basis, migrants from Ukraine and Moldova become participants of the state program on compatriots resettlement in Karelia.

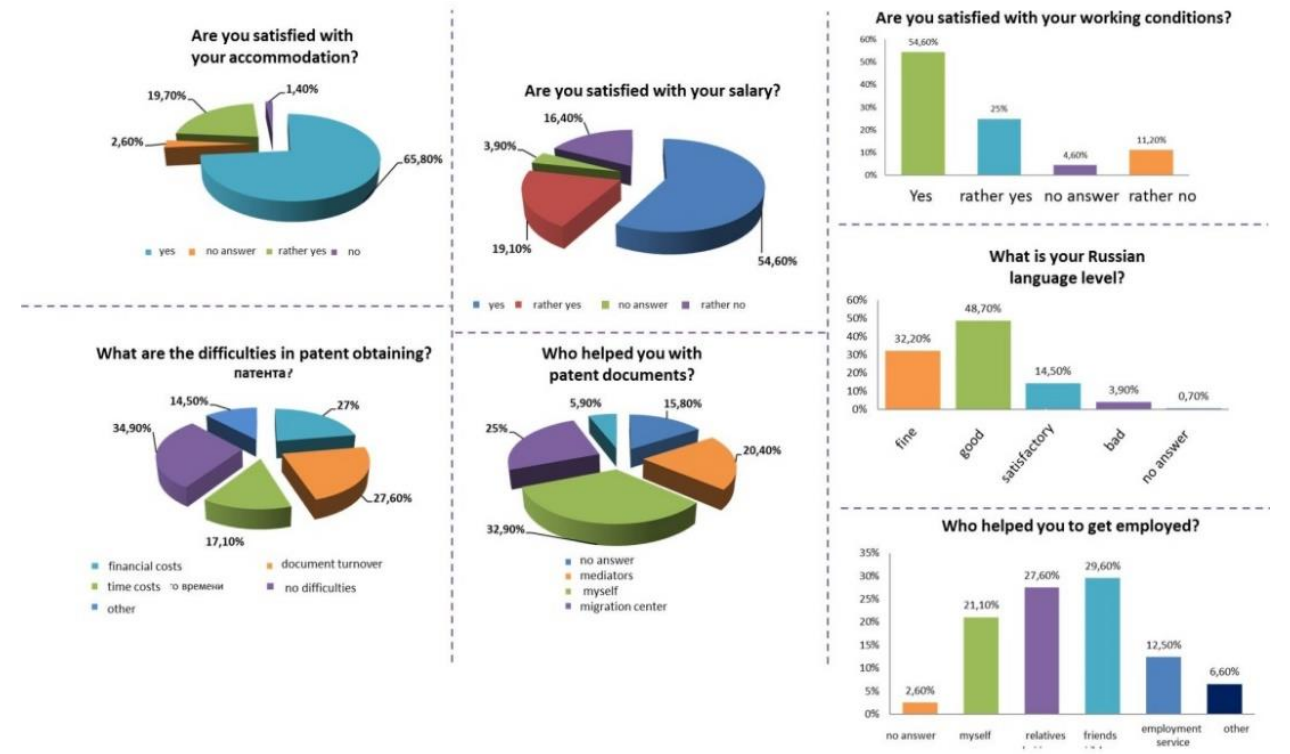

Fig. 5. Module «migrants' social adaptation» of Multicultural barometer.

The Multicultural barometer module "migrants' integration" is complemented with both migrants and host community surveys results. We've tried to assess how migrants are being integrated into local culture.

According to migrants' survey results, it was found that $68.4 \%$ are positive towards other nationalities and religions in their environment (Figure 6). At the same time $57.9 \%$ of respondents said that they do not attend theaters, cinema, museums, exhibitions, i.e. migrants do not integrate into local culture. Nevertheless, communication process with the host community representatives occurs on a regular basis - for $84 \%$ of migrants it happens every day. 
Figure 6 shows a chart based on host community survey results. The goal of this survey is to obtain sound and reliable data on performance indicators.

The majority of citizens ( $83.9 \%$ of respondents) evaluate interethnic relations at the Republic of Karelia positively considering these relations as good, calm, without hostility or irritation to some other ethnic and cultural groups. Given the high willingness to cooperate with representatives of other ethnic and cultural groups (88.7\% of respondents), we do consider level of tolerance to some other cultural code as satisfactory.

It also turned out that Karelian northern municipalities are traditionally more tolerant (Muezersky, Belomorsky, Kemsky, Kalevalsky) comparing to southern ones.
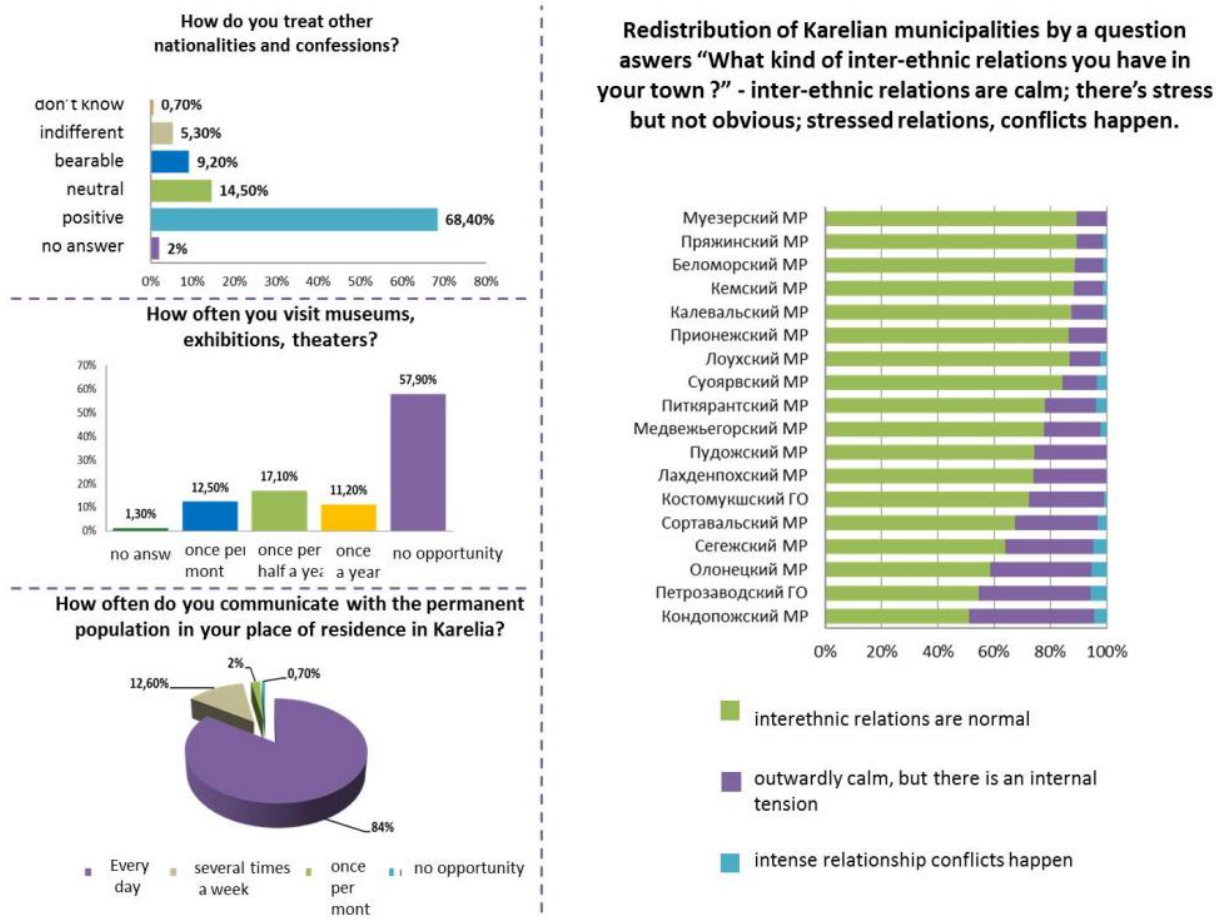

Fig. 6. Module «migrants' integration» of Multicultural barometer.

As a result accumulated data for 4 modules of Multicultural barometer ("labor market", "national identity", “migrants' social adaptation", “migrants' integration”)was selected for further Karelian municipalities clusterization. The key data for clusterization is dealing with:

- interethnic relations evaluation by host community (based on host community survey);

- migrants' level of education according to survey results;

- distribution of respondents bytheir country of origin(based on migrants' survey);

- activity of Centers on Interethnic Cooperation at the Republic of Karelia.

The following indicators were selected for each of 18 municipalities at the Republic of Karelia:

- Number of arrivals (Migration with the CIS countries), people

- Migration growth (Migration with the CIS countries), people

- Investments in fixed assets, thousand rubles

- Revenues of the local budget, thousand rubles. 
- Share of the population of the Republic of Karelia that believes interethnic relations in the region to be normal, $\%$.

Microsoft Analysis Services data mining tools were applied, which isa part of the Microsoft SQL Server database management system. For convenience the analysis was carried out in Excel using Excel Add-Ins Analysis Services MS SQL Server: both table analysis tools and data mining client for Excel.

The following input factors were selected which theoretically might influence host community in a positive way (on relations with migrants):

- Number of arrivals (Migration with the CIS countries), people

- Migration growth (Migration with the CIS countries), people

- Investments in fixed assets, thousand rubles

- Revenues of the local budget, thousand rubles.

As a result there were identified several levels \{Very low, Low, Medium, High, Very high\}, where

- Very low: $<0.346$;

- Low: 0.346 - 0.408;

- Average: $0.408-0.483$;

- High: $0.483-0.563$;

- Very high: $>=0.564$.

As a result Multicultural barometer an infographic tool demonstrating migration tension in terms of municipalities by the example of the Republic of Karelia was developed. Three regional clusters were distinguished - tense areas, positive areas and neutral areas. According to cluster analysis results, only 3 out of 18 municipalities belong to stressed areas at the Republic of Karelia (Kondopoga, Segezha, Olonets marked with orange colour). Ten years after Kondopoga events it could be argued that Kondopozhsky region is still stressed, however, the most acute situation is currently developing in Segezhsky region. Neutral regions: Kalevalsky region where Karelian indigenous people live; international areas along Ladogalake (Lakhdenpohsky, Sortavalsky and Pitkyarantsky); Kostomukshsky border region in the far north.

\section{Conclusion}

It shall be noted that currently both integration and migration policies are implemented on a system basis at the Republic of Karelia , the basis for that - both civil society actors and government bodies sustainable interaction. As a result, Centers on interethnic cooperation were created in all municipalities of the Republic of Karelia.

Multicultural barometer as a tool for migration monitoring and control was approbated by the example of the Republic of Karelia under the auspices of the Ministry on ethnic issues of the Republic of Karelia. The research findings were highly appreciated by regional authorities and were recommended to the Strategic Initiatives Agency as best regional practice for further implementation in other Russian regions. In 2017 Multicultural Barometer was approbated by the example of Khanty-Mansiysky Autonomous DistrictUgra [24].

The tool described in the article shall be replicated in order to quantify migration indicators in other Russian regions allowing perceiving both migration monitoring and control at a highly-detailed level - municipal. 


\section{Acknowledgment:}

The study was supported by a grant from the Russian Science Foundation, project No. 2118-00500 "Institutional engineering of monocities in the Arctic zone - modernization and sustainable development"

\section{References}

1. FADN (2018) http://fadn.gov.ru/news/2018/02/08/3540-fadn-rossii-organizovalovserossiyskiy-seminar-posvyaschennyy-monitoringu-mezhnatsionalnyh-otnosheniy

2. Decree of the President of the Russian Federation. Ensuring interethnic harmony (2012)

3. D. Ushakov, Urbanization and Migration as Factors Affecting Global Economic Development, 1-317 (2014)

4. A. Richmond, J. of Refugee Studies 6, 7-24 (1993)

5. D. Horowitz, Structure and Strategy in Ethnic Conflict (1998)

6. E. Lee, Demography 3, 47-57 (1966)

7. D. Ushakov, T. Auliandri, IOP Conference Series: Materials Science and Engineering 753(8), 082024 (2020)

8. S. Stouffer, American Sociological Review 5, 845-867 (1940)

9. A.H. Tran et al., International Journal of Recent Technology and Engineering 8(2.11), 3883-3888 (2019)

10. E. Ravenstein, J. of Royal Statistical Society 52, 241-305 (1889)

11. D. Massey et al., Population and Development Review 19(3), 431-466 (1993)

12. M. Gordon, International Migration Digest 1(2), 232-235 (1964)

13. M. Kritz, A global picture of contemporary immigration patterns (1989)

14. T. Eriksen, Ethnicity and Nationalism: Anthropological Perspectives (London, Pluto Press, 2002)

15. Y. Soysal, Limits of Citizenship: Migrants and Postnational Membership in Europe (USA, University Chicago Press, 1995)

16. H.L.T. Mai et al., International Journal of Recent Technology and Engineering 8(2.11), 3876-3882 (2019)

17. O. Brednikova, Ethnographic review 3, 32-47 (2017)

18. M. Kaiser \& O. Brednikova, Migration and the national state (2004)

19. M. Ihnatenko et al., International Journal of Economics and Business Administration 7(2), 290-301 (2019)

20. M. Pitukhina et al., Geography, Environment, Sustainability 12(2), 6-12 (2019)

21. D. Ushakov, E. Kozlova, Actual Problems of Economics 163(1), 391-397 (2015)

22. D. Ushakov, E. Rubinskaya, Immigration and the Current Social, Political, and Economic Climate: Breakthroughs in Research and Practice 2, 625-643 (2018)

23. D Ushakov et al., Espacios 40(34) (2019)

24. M Vinichenko et al., Espacios 40(19) (2019) 